\title{
MEAN ARTERIAL PRESSURE DAN INDEKS MASSA TUBUH DENGAN KEJADIAN PREEKLAMPSIA PADA IBU HAMIL DI RUMAH SAKIT BHAYANGKARA MAKASSAR
}

\section{Mean Arterial Pressure and Body Mass Index with the Preeklamsia in Pregnancy at Bhayangkara Makassar Hospital}

\author{
Zulaeha A Amdadi ${ }^{1}$, Afriani ${ }^{2}$, Fitriati Sabur ${ }^{3}$ \\ Jurusan Kebidanan Poltekkes Kemenkes Makassar \\ afriani@poltekkes-mks.ac.id \\ Hp. 081342412307
}

\begin{abstract}
Hypertension is one of the main risk factors for death worldwide. Indonesia is the fifth country in terms of hypertension in the Southeast Asian Region, which is $15 \%$ of the entire population. Hypertension in pregnancy (HDK) affects about $10 \%$ of all pregnant women worldwide. These diseases and conditions include preeclampsia and eclampsia, gestational hypertension and chronic hypertension. One of the early detection efforts for the incidence of preeclampsia in pregnant women is by measuring the Body Mass Index (BMI), Mean Arterial Pressure (MAP). The purpose of this study was to determine the relationship between Mean Arterial Pressure and body mass index with the incidence of preeclampsia in pregnant women in hospital. Bhayangkara Makassar in 2019. This type of research is a hybrid research that combines two methods of time approach that is cross sectional and prospective cohort. The study population was all pregnant women who examined their pregnancy at the hospital. Bhayangkara Makassar with gestational age> 20 weeks, who experienced preeclampsia and not preeclampsia as many as 2,160 people. The sampling method uses accidental sampling. The process of collecting data is done by measuring blood pressure, height and weight in pregnant women who come to check their pregnancy. Analysis of research data with univariate, bivariate analysis using the chi square test. The results showed that there was a relationship between MAP and BMI with the incidence of preeclampsia with $p$ $=0.00$. It is recommended to institutions / health facilities to prevent the occurrence of preeclampsia and eclampsia early prevention, especially in high-risk groups that aim to identify the possibility of preeclampsia in pregnant women since early pregnancy.
\end{abstract}

Keywords: Mean Arterial Pressure, body mass index, preeclampsia.

\section{ABSTRAK}

Hipertensi merupakan salah satu faktor risiko utama kematian di seluruh dunia. Indonesia merupakan Negara dengan dengan peringkat kelima dalam hal kejadian hipertensi di Kawasan Asia Tenggara yaitu sebanyak $15 \%$ dari seluruh penduduk. Hipertensi dalam kehamilan (HDK) mempengaruhi sekitar $10 \%$ dari semua perempuan hamil diseluruh dunia. Penyakit dan kondisi ini termasuk preeeklampsia dan eklampsia, hipertensi gestasional dan hipertensi kronik. Salah satu upaya deteksi dini terhadap kejadian preeklampsia pada ibu hamil adalah dengan pengukuran Indeks Massa Tubuh (IMT), Mean Arterial Pressure (MAP). Tujuan penelitian untuk mengetahui hubungan antara Mean Arterial Pressure dan indeks massa tubuh dengan kejadian preeklampsia pada ibu hamil di RS. Bhayangkara Makassar tahun 2019. Jenis penelitian ini adalah penelitian hybrid yaitu menggabungkan dua metode pendekatan waktu yaitu cross sectional dan cohort prospektif. Populasi penelitian adalah semua ibu hamil yang memeriksakan kehamilannya di RS. Bhayangkara Makassar dengan usia kehamilan > 20 minggu, yang mengalami preeklampsia dan tidak preeklampsia sebanyak 2.160 orang. Metode sampling menggunakan accidental sampling. Proses pengumpulan data dilakukan dengan melakukan pengukuran tekanan darah, tinggi badan dan berat badan pada ibu hamil yang datang memeriksakan kehamilannya. Analisa data hasil penelitian dengan analisis univariat, bivariat dengan menggunakan uji chi square. Hasil penelitian menunjukkan bahwa ada hubungan MAP dan IMT dengan kejadian preeklampsia dengan nilai $p=0,00$. Disarankan kepada institusi/fasilitas kesehatan untuk untuk mencegah hal terjadinya preeklampsia dan eklampsia pencegahan dini terutama pada kelompok yang berisiko tinggi yang bertujuan untuk mengidentifikasi kemungkinan terjadinya preeklampsia pada wanita hamil sejak awal kehamilan.

Kata Kunci : Mean Arterial Pressure, indeks massa tubuh, preeklampsia. 


\section{PENDAHULUAN}

Hipertensi merupakan faktor penting yang mempengaruhi hampir satu milyar orang diseluruh dunia dan menyebabkan sekitar 7,1 kematian pertahun di usai dewasa (Firmansyah dkk, 2017).

World Health Organization (WHO)
dalam $\quad$ Fatmawati, dkk (2017) mengemukakan bahwa Hipertensi merupakan salah satu faktor risiko utama kematian di seluruh dunia, diperkirakan sekitar 9,4 juta kematian disebabkan oleh hipertensi. Secara global, prevalensi hipertensi pada orang dewasa 18 tahun ke atas sekitar $22 \%$ pada tahun 2014 ..

Hipertensi dalam kehamilan (HDK) mempengaruhi dari semua perempuan hamil di seluruh dunia. Penyakit dan kondisi ini termasuk preeclampsia dan eklampsia, hipertensi gestasional dan hipertensi kronik. Hipertensi dalam kehamilan adalah penyebab penting morbiditas akut berat, cacat jangka panjang dan kematian ibu serta bayi. .

$$
\text { Puspitasari (2015) dalam }
$$
penelitiannya menyebutkan bahwa seseorang memiliki memiliki indeks massa tubuh berlebih (obesitas) berisiko 3 kali lebih tinggi untuk terkena penyakit hipertensi dibandingkan seseorang yang indeks massa tubuhnya dalam batas normal. Laura Reyes et al. (2012) dalam penelitiannya didapatkan seseorang dengan Massa Tubuh (IMT) $>31 \mathrm{Kg} / \mathrm{m}^{2}$ menyebabkan 2 kali lebih tinggi terjadinya hipertensi. Kedua penelitian tersebut sejalan dengan penelitian yang dilakukan oleh Gudnadóttir, T. A. et al. (2016) bahwa ibu hamil dengan IMT kategori Overweight dapat menyebabkan 1,8 kali lebih besar kemungkinan terjadinya hipertensi dan ibu hamil dengan IMT kategori Obese menyebabkan 3,1 lebih besar kemungkinan terkena penyakit hipertensi.

Hasil penelitian yang dilakukan oleh Kundu dkk (2017), MAP dapat digunakan sebagai variable yang representative untuk mengidentifikasi tekanan darah berdasarkan tekanan sistolik dan diastolic. Hipertensi dalam kehamilan berdampak negative terhadap kondisi ibu dan janin antara lain: pada ibu dapat berlanjut menjadi preeklampsia, eklampsia sedangkan pada janin dapat terjadi: Intra uterine growth retardation, asfiksia neonatorum, gawat janin dan intra uterine fetal death.

Suprihatin $\begin{array}{r}(2015) \\ \text { penelitiannya menjelaskan }\end{array}$ dalam
bahwa kombinasi dari IMT, MAP dan ROT dinyakatan $90 \%$ terkena preeklampsia jika memiliki dua atau lebih tanda positif dan dari $85 \%$ yang dinyatakan positif dengan pengukuran IMT, MAP dan ROT tersebut setelah dilakukan pengamatan lebih lanjut ternyata $90 \%$ memang preeklampsia.

Jika hipertensi tidak dapat di antisipasi maka akan mengarah ke preeklamsia yang dapat meningkatkan resiko komplikasi selama kehamilan seperti kerusakan sistem atau organ lainnya yang berefek jangka panjang. Oleh karena itu, untuk mencegah hal tersebut diperlukan pencegahan dini terutama pada kelompok yang berisiko tinggi yang bertujuan untuk mengidentifikasi kemungkinan terjadinya hipertensi pada wanita hamil sejak awal kehamilan sehingga dapat dilakukan pencegahan dengan obat tertentu, pengawasan ketat, diagnosis yang lebih dini dan pemberian intervensi tepat waktu. Deteksi lebih dini dapat dilakukan dengan perhitungan Mean Arterial Pressure (MAP) dan Indeks Massa Tubuh (IMT)..

Tujuan umum penelitian ini adalah Mengetahui hubungan antara mean arterial pressure dan indeks massa tubuh dengan kejadian preeklampsia pada ibu hamil di RS. Bhayangkara Makassar tahun 2019.

\section{METODE PENELITIAN}

Penelitian ini dilaksanakan di RS. Bhayangkara Makassar. Desain penelitian menggunakan desain cross sectional study dan cohort prospektif. Populasi dalam penelitian ini adalah semua ibu hamil di yang memeriksakan kehamilannya di RS. Bhayangkara Makassar dengan usia kehamilan $\geq 20$ minggu, yang mengalami hipertensi dan tidak hipertensi. Sampel penelitian adalah semua ibu hamil di yang memeriksakan kehamilannya di RS. Bhayangkara Makassar dengan usia kehamilan $\geq 20$ minggu, yang mengalami hipertensi dan tidak hipertensi dengan teknik accidental sampling yang berjumlah 95 orang kelompok kasus dan 95 orang kelompok kontrol.

Sumber data penelitian adalah data primer yang diperoleh langsung dari ibu hamil melalui pengukuran tekanan 
darah dan indeks massa tubuh. Teknik analisis data yang digunakan adalah analisis univariat dan analisis bivariat dengan menggunakan uji Pearson chiSquare.

\section{HASIL DAN PEMBAHASAN}

Penelitian ini dilaksanakan di RS. Bhayangkara Makassar Makassar. Hasil analisis disajikan dalam bentuk tabel yang dilengkapi dengan penjelasan tabel 1 .

Tabel 1 menunjukkan jumlah responden terbanyak pada umur 20-35 tahun (50,6\%) pada kelompok preeklampsia. Jumlah paritas terbanyak adalah paritas $1(63,6 \%)$ pada kelompok PEMBAHASAN

Mean Arterial Pressure (MAP) adalah rata-rata nilai tekanan arterial dinilai dari pengukuran diastole dan sistol, kemudian ditentukan nilai rata-rata atrerin. MAP dikatakan positif jika hasil > 90 $\mathrm{mmHg}$, dan negatif jika hasilnya $<90$ $\mathrm{mmHg}$. Pada wanita hamil resiko rendah, rata-rata tekanan darah arteri pada trimester kedua lebih baik menjadi prediktor preeklampsia dibanding tekanan darah sistolik atau tekanan darah diastolik (Suprihatin. 2015).

Hasil penelitian menunjukkan bahwa MAP positif (> $90 \mathrm{mmHg}$ ) secara signifikan berbeda pada kelompok normal tensi dengan kelompok hipertensi pada usai kehamilan $\geq 20$ minggu, 27 minggu dan 32 minggu. Peluang ibu hamil dengan MAP positif untuk menderita preeklampsia pada usia kehamilan $\geq 20$ minggu, 27 minggu dan 32 minggu dengan nilai $p=0,000$. Sejalan dengan temuan (Cnosen J.s et al., 2008) pada trimester 2 dengan MAP $\geq 90 \mathrm{~mm} \mathrm{Hg}$ menunjukkan 4 kali kemungkinan terjadinya hipertensi dalam kehamilan.

Hasil penelitian yang dilakukan oleh Kundu dkk (2017), MAP dapat digunakan sebagai variable yang representative untuk mengidentifikasi tekanan darah berdasarkan tekanan sistolik dan diastolic. Hipertensi dalam kehamilan berdampak negative terhadap kondisi ibu dan janin antara lain: pada ibu dapat berlanjut menjadi preeklampsia, eklampsia sedangkan pada janin dapat terjadi: Intra uterine growth retardation, asfiksia neonatorum, gawat janin dan intra uterine preeklampsia. Dari data tingkat pendidikan menunjukkan tingkat pendidikan SMP yang tertinggi $(57,7 \%)$ pada kelompok preeklampsia. Dari data pekerjaan, mayoritas ibu yang menjadi responden tidak bekerja atau ibu rumah tangga (51,6\%).

Tabel 2. menunjukkan bahwa MAP pada usia kehamilan $\geq 20$ minggu, 28 minggu dan 32 minggu memiliki hubungan yang bermakna terhadap hipertensi dalam kehamilan dengan $p 0,000$.

Tabel 3 menunjukkan bahwa IMT pada kunjungan usia kehamilan 27 minggu memiliki hubungan yang bermakna terhadap hipertensi dalam kehamilan dengan $p$ value $<0,05$.

fetal death.

Suprihatin (2015) dalam penelitiannya menjelaskan bahwa kombinasi dari IMT, MAP dan ROT dinyakatan $90 \%$ terkena preeklampsia jika memiliki dua atau lebih tanda positif dan dari $85 \%$ yang dinyatakan positif dengan pengukuran IMT, MAP dan ROT tersebut setelah dilakukan pengamatan lebih lanjut ternyata $90 \%$ memang preeklampsia.

Jika hipertensi tidak dapat di antisipasi maka akan mengarah ke preeklamsia yang dapat meningkatkan resiko komplikasi selama kehamilan seperti kerusakan sistem atau organ lainnya yang berefek jangka panjang. Oleh karena itu, untuk mencegah hal tersebut diperlukan pencegahan dini terutama pada kelompok yang berisiko tinggi yang bertujuan untuk mengidentifikasi kemungkinan terjadinya hipertensi pada wanita hamil sejak awal kehamilan sehingga dapat dilakukan pencegahan dengan obat tertentu, pengawasan ketat, diagnosis yang lebih dini dan pemberian intervensi tepat waktu. Deteksi lebih dini dapat dilakukan dengan perhitungan Mean Arterial Pressure (MAP) dan Indeks Massa Tubuh (IMT).

Secara signifikan berbeda pada kelompok normal dengan kelompok preeklampsia pada usiai kehamilan $\geq 20$ minggu, 27 minggu dan 32 minggu. Peluang ibu hamil dengan IMT tidak normal untuk menderita preeklampsia pada usia kehamilan $\geq 20$ minggu, 27 minggu dan 32 minggu dengan nilai $p=0,000$. Ini sejalan dengan penelitian yang dilakukan oleh (Gudnadóttir, T. A. et al. 2016) bahwa ibu hamil dengan kategori Overweight memiliki 
risiko 2 kali lipat menyebabkan hipertensi dalam kehamilan dan IMT kategori Obese akan mengalami 3 kali lipat jatuh kepada hipertensi, semakin besar angka IMT ibu hamil maka semakin besar pula kemungkinan terkena penyakit hipertensi.

$$
\text { Puspitasari (2015) dalam }
$$

penelitiannya menyebutkan bahwa seseorang memiliki memiliki indeks massa tubuh berlebih (obesitas) berisiko 3 kali lebih tinggi untuk terkena penyakit hipertensi dibandingkan seseorang yang indeks massa tubuhnya dalam batas normal. Laura Reyes et al. (2012) dalam penelitiannya didapatkan seseorang dengan Massa Tubuh (IMT) $>31 \mathrm{Kg} / \mathrm{m}^{2}$ menyebabkan 2 kali lebih tinggi terjadinya hipertensi. Kedua penelitian tersebut sejalan dengan penelitian yang dilakukan oleh Gudnadóttir, T. A. et al. (2016) bahwa ibu hamil dengan IMT kategori Overweight dapat menyebabkan 1,8 kali lebih besar kemungkinan terjadinya hipertensi dan ibu hamil dengan IMT kategori Obese menyebabkan 3,1 lebih besar kemungkinan terkena penyakit hipertensi.

\section{KESIMPULAN}

Ada hubungan Mean Arterial Preassure dan Indeks Massa Tubuh dengan kejadian preeklampsia.

\section{SARAN}

Pencegahan pada kelompok yang berisiko tinggi bertujuan untuk mengidentifikasi kemungkinan terjadinya preeklampsia pada wanita hamil sejak awal kehamilan sehingga dibutuhkan deteksi lebih dini.

\section{REFERENSI}

ACOG. (2013). Hypertension in pregnancy. Amerika Serikat

Ardiana, Siti. (2012). Hubungan IMT dengan tekanan darah di Masyarakat Kec. Pakuncen Wirobrajan Yogyakarta. (online) http://digilib.uniayogya.ac.id. Di Akses tanggal 20 November 2018.

Cnossen, J. S. et al. 2008. Accuracy of mean arterial pressure and blood ressure measurements in predicting pre-eclampsia: systematic view and meta-analysis. BMJ (Clinical research ed.)

Cunningham F, G et. al. 2013 Obstetri Williams (William Obstetri). Jakarta:EGC
Fatmawati, dkk. (2017). Pengaruh Pemberian Pisang Ambon terhadap penurunan tekanan darah pada lansia. Jurnal Institut Teknologi Sains dan Kesehatan (ITS) PKU Muhammadiyah 2019.

Firmansyah, dkk. (2017). Faktor-faktor yang berhubungan dengan dukungan keluarga dalam pencegahan primer hipertensi. Jurnal Keperawatan Padjajaran Universitas Padjajaran Bandung, vol 2, No 5 (2017).

Hidayat Arif. 2013. Pengaruh terapi oksigen terhadap MAP pada pasien cedera kepala di IGD RSUD Prof. Dr.Margono Soekarjo. Fak IImu Kesehatan-Keperawatan

Universitas Muhammadiyah Purwokerto . Oktober 2018.

Kementrian Kesehatan Republik Indonesia. 2011. Pedoman Interpretasi DataKlinik.Availableat: https://www.researchgate.net/profil e/Fauna Herawati/publication/30 3523819_Pedoman_Interpretasi_D ata_Klinik/links/5746c1db08ae2 98602fa0bb4/PedomanInterpretasi-Data-Klinik.pdf Kementrian Kesehatan. 2014. Profil Kesehatan Indonesia Tahun 2013, Jakarta: Kementerian Kesehatan RI. doi: 351.770 .212 Ind P.

KEMENKES RI. 2013. Buku Saku Pelayanan Kesehatan lbu di Fasilitas Kesehatan Dasar dan Rujukan : Pedoman Bagi Tenaga Kesehatan. Jakarta : WHO, IDI dan IBI.

Kementerian Kesehatan RI. (2015). Profil Kesehatan Indonesia 2014. Jakarta: Kementerian Kesehatan RI.

Kottke, dkk. 2017. Mean Arterial Pressure Classification: A Better Tool for Statistical Interpretation of Blood Pressure Related Risk Covariates. Cardiology and Angiology: An International Jurnal Article no CA 30255. ISSN 2347-520X (online) http://.sciencedomain.org Diakses 10 November 2018.

Notoatmodjo, S. (2011). Metodologi Penelitian Kesehatan. Jakarta: Rineka Cipta.

Oxford University Hospitals. 2014. Pregnancy and Body Mass Indeks (BMI). United Kingdom 
Peterson, H. 2010. Genetic Study Of Pre Eclampsia. Departement Of Bioscience And Butrition Karolinska Institutet, Stockholm, Sweden. Available at:https://openarchive.ki.se/xmlui/bit stream/handle/10616/39596/thesis. pdf? sequence $=1$.

POGI. 2016. Diagnosis Dan Tata Laksana Pre-Eklamsia. Indonesia (25 September 2017)

Porth, Carol. 2009. Essentials Of Pathophysiology. Edisi 3. Hal 422. USA: Lippincott Williams \& Wilkins.

Prawirohardjo S. 2010. Hipertensi Dalam Kehamilan: IImu Kebidanan. Jakarta. Yayasan Pustaka Sarwono Prawirohardjo.

Prawirohardjo Sarwono, S. d. (2010). IImu Kebidanan Sarwono Prawirohardjo (Vol. III). (M. S. Prof. dr. Abdul Bari Saifuddin, Penyunt.) Jakarta: PT.
Bina Pustaka Sarwono

Prawirohardjo.

Sartika. 2017. Faktor-faktor resiko dan angka kejadian hipertensi pada penduduk Palembang. Jurnal ilmu kesehatan masyarakat, November 2017. 8 (3):180-191.

Suprihatin, E. and Norontoko, D. A. (2016). Prediction of Preeclampsia by a Combination of Body Mass Index ( BMI ), Mean Arterial Pressure ( MAP ), and Roll Over Test ( ROT ). Jurnal Ners Unair 2016.

WHO. 2014.A Global brief on hypertension silent killer, global public health crisis. Switzerland; WHO

WHO. 2017. Managing complications in pregnancy and childbirth (MCPC) : A Guide for midwives and doctors highlights from the world health organization's 2017, second edition. 
Tabel 1. Karakteristik responden tentang hubungan mean arterial pressure dan indeks massa tubuh dengan kejadian preeklampsia pada ibu hamil di RS. Bhayangkara Makassar

\begin{tabular}{lcccc}
\hline \multicolumn{1}{c}{ Variabel } & \multicolumn{2}{c}{ Preeklampsia } & \multicolumn{2}{c}{ Tidak preeklampsia } \\
& $\mathrm{F}$ & $\%$ & $\mathrm{~F}$ & $\%$ \\
\hline Umur (thn) & 8 & 57,1 & 6 & 42,9 \\
$<20$ & 79 & 50,6 & 77 & 49,4 \\
$20-35$ & 8 & 40,0 & 12 & 60,0 \\
$>35$ & & & & \\
Paritas & 42 & 63,6 & 24 & 36,4 \\
1 & 47 & 39,8 & 71 & 60,2 \\
$2-4$ & 6 & 100 & 0 & 0 \\
$\geq 5$ & 12 & 52,2 & 11 & 47,8 \\
Pendidikan & 15 & 57,7 & 11 & 42,3 \\
SD & 42 & 48,3 & 45 & 51,7 \\
SMP & 26 & 48,1 & 28 & 51,9 \\
SMA & & & & \\
PT & 31 & 47,0 & 35 & 53,0 \\
Pekerjaan & 64 & 51,6 & 60 & 48,4 \\
Bekerja & & & & \\
Tidak bekerja & Sumber : Data Primer tahun 2019 & & &
\end{tabular}

Tabel 2. Hubungan mean arterial pressure dengan kejadian preeklampsia pada ibu hamil di RS. Bhayangkara Makassar

\begin{tabular}{|c|c|c|c|c|c|}
\hline \multirow{2}{*}{ Variabel } & \multicolumn{2}{|c|}{ Preeklampsia } & \multicolumn{2}{|c|}{ Tidak preeklampsia } & \multirow[b]{2}{*}{$p$} \\
\hline & $\mathrm{N}$ & $\%$ & $\mathrm{~N}$ & $\%$ & \\
\hline MAP UK $\geq 20 \mathrm{mgg}$ & & & & & \\
\hline Positif & 95 & 65,5 & 50 & 34,5 & 0,000 \\
\hline Negatif & 0 & 0,0 & 45 & 100 & \\
\hline MAP UK28 mgg & & & & & \\
\hline Positif & 89 & 78,1 & 25 & 21,9 & 0,000 \\
\hline $\begin{array}{c}\text { Negatif } \\
\text { MAP UK32 minggu }\end{array}$ & 6 & 7,9 & 70 & 92,1 & \\
\hline Positif & 85 & 65,4 & 45 & 34,6 & 0,000 \\
\hline Negatif & 10 & 16,7 & 50 & 83,3 & \\
\hline
\end{tabular}


Tabel 3. Hubungan indeks massa tubuh dengan kejadian preeklampsia pada ibu hamil di RS. Bhayangkara Makassar

\begin{tabular}{|c|c|c|c|c|c|}
\hline \multirow{3}{*}{ Variabel } & \multicolumn{2}{|c|}{ Preeklampsia } & \multicolumn{2}{|c|}{ Tidak preeklampsia } & \multirow{3}{*}{$p$} \\
\hline & & & & & \\
\hline & $\mathrm{N}$ & $\%$ & $\mathrm{n}$ & $\%$ & \\
\hline \multicolumn{6}{|c|}{ IMT UK $\geq 20$ minggu } \\
\hline Normal & 20 & 20,0 & 80 & 80,0 & 0,000 \\
\hline Tidak normal & 75 & 83,3 & 15 & 16,7 & \\
\hline \multicolumn{6}{|c|}{ IMT UK28 minggu } \\
\hline Normal & 14 & 15,9 & 74 & 84,1 & 0,000 \\
\hline Tidak normal & 81 & 79,4 & 21 & 20,6 & \\
\hline \multicolumn{6}{|c|}{ IMT UK32 minggu } \\
\hline Normal & 11 & 13,6 & 70 & 86,4 & 0,000 \\
\hline Tidak normal & 84 & 77,1 & 25 & 22,9 & \\
\hline
\end{tabular}

Sumber data primer tahun 2019 